\title{
8
}
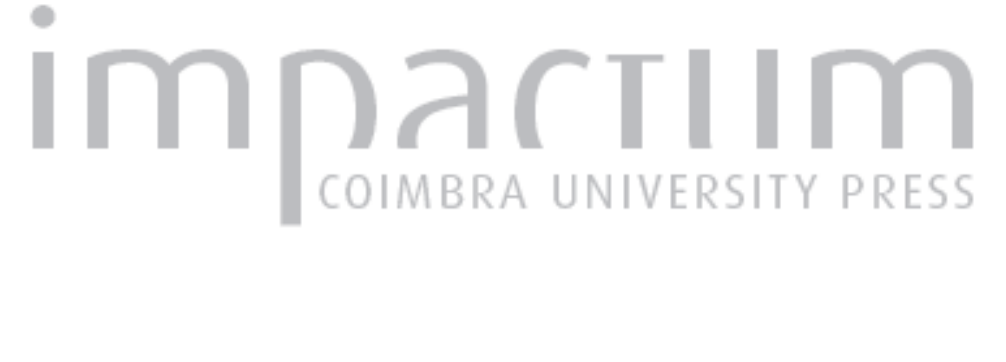

\section{Zonas costeiras continentais portuguesas: questões prévias sobre a ecologia humana das zonas costeiras e os conflitos pelo uso e a regulação dos territórios}
Autor(es):
Craveiro, João Lutas; Pires, Iva Miranda; Almeida, Isabel Duarte de; Antunes, Oscar Emanuel

\section{Publicado por: CEDOUA}

URL

persistente:

URI:http://hdl.handle.net/10316.2/37566

DOI:

DOI:http://dx.doi.org/10.14195/2182-2387_24_8

Accessed : $\quad$ 26-Apr-2023 15:24:29

A navegação consulta e descarregamento dos títulos inseridos nas Bibliotecas Digitais UC Digitalis, UC Pombalina e UC Impactum, pressupõem a aceitação plena e sem reservas dos Termos e Condições de Uso destas Bibliotecas Digitais, disponíveis em https://digitalis.uc.pt/pt-pt/termos.

Conforme exposto nos referidos Termos e Condições de Uso, o descarregamento de títulos de acesso restrito requer uma licença válida de autorização devendo o utilizador aceder ao(s) documento(s) a partir de um endereço de IP da instituição detentora da supramencionada licença.

Ao utilizador é apenas permitido o descarregamento para uso pessoal, pelo que o emprego do(s) título(s) descarregado(s) para outro fim, designadamente comercial, carece de autorização do respetivo autor ou editor da obra.

Na medida em que todas as obras da UC Digitalis se encontram protegidas pelo Código do Direito de Autor e Direitos Conexos e demais legislação aplicável, toda a cópia, parcial ou total, deste documento, nos casos em que é legalmente admitida, deverá conter ou fazer-se acompanhar por este aviso. 


\section{RevGEDOUA}

N.224_Ano XII_ 2.09

> Doutrina

Gestāo Integrada da Zona Costeira Portuguesa

Fernanda do Carmo

E um dia a Falésia veio Abaixo. Pisco de Erosāo da Orla Costeira, Prevenção e Hesponsabilizaçāo

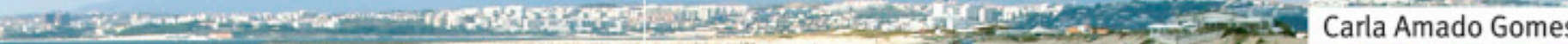

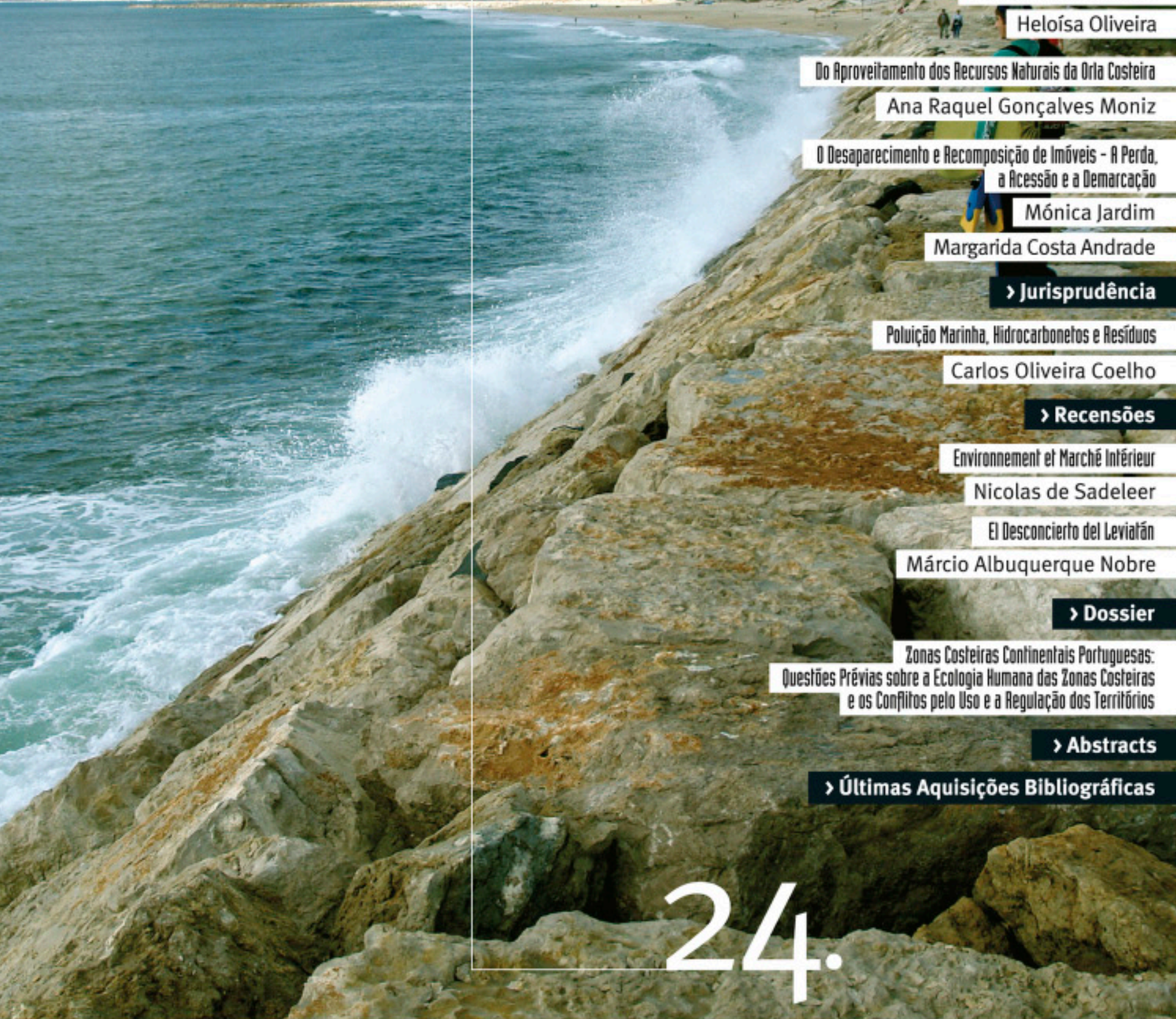




\section{Zonas costeiras continentais portuguesas: \\ Questões prévias sobre a ecologia humana das zonas costeiras e os conflitos pelo uso e a regulação dos territórios}

O Projecto RENCOASTAL, Regulações e Conflitos Ambientais Devido à Erosão Costeira (PTDC/CS-SOC/103202/2008) é um projecto de investigação financiado pela Fundação para a Ciência e Tecnologia, promovido pelo Laboratório Nacional de Engenharia Civil em parceria com a Faculdade de Ciências Sociais e Humanas da Universidade Nova de Lisboa. O Projecto RENCOASTAL explora as contradições entre os modelos de desenvolvimento e as regulações ambientais, tendo como objectivo principal contribuir para uma gestão integrada das zonas costeiras continentais portuguesas. 0 projecto, iniciado nos começos de 2010 e com termo previsto para 2013, apura nesta fase da sua execução as homogeneidades e diferenças socioeconómicas e ambientais das zonas costeiras continentais portuguesas, com recurso a técnicas descritivas e à selecção de casos de estudo.

Os casos de estudo integram a fase seguinte do projecto, incidindo sobre o carácter da consulta pública, no âmbito de instrumentos de ordenamento do território e, em particular, sobre a gestão das zonas costeiras continentais portuguesas. Assim, o projecto envolve a execução de diversas fases sequenciais desde as componentes iniciais descritivas até à análise das percepções sociais do risco e da exposição humana e a discriminação de conteúdos de formação cívica para sustentabilidade. Envolve ainda a análise sociológica dos conflitos ambientais ${ }^{1}$, dimensão fulcral para a compreensão das possibilidades de regulação política das interdependências entre os sistemas sociais e os sistemas naturais, em contextos críticos como são as zonas costeiras sujeitas ao risco de erosão. As interdependências entre os sistemas sociais e naturais são mediadas por intervenções técnicas ao nível das infra-estruturas e a densidade demográfica e a evolução urbana fizeram com que este tipo de intervenções não possa ser dispensado. 0 projecto discute, assim também, o sentido das intervenções (mais ou menos intrusivas) e a ponderação de soluções alternativas através da auscultação de peritos e percepção dos impactos sociais das alterações climáticas.

Nesta fase inicial do projecto procedeu-se a uma caracterização geral das zonas costeiras, com recurso à unidade de análise socioeconómica NUTIII para dar maior coerência à discriminação espacial de dados censitários e à identificação de homogeneidades estruturais. Apesar da heterogeneidade socioeconómica das zonas costeiras é possível, com recurso à técnica de análise de clusters, discriminar semelhanças através do somatório das diferenças entre valores de variáveis. Seleccionaram-se 55 variáveis (em anexo), tendo como base em estudo desenvolvido anteriormente sobre as zonas costeiras ${ }^{2}$, integrando neste projecto RENCOASTAL variáveis de carácter «não-social» (medição de zonas de segurança a partir de

\footnotetext{
${ }^{1}$ No limite, o conflito ambiental opõe os modos de apropriação e humanização do território ao tipo de regulações ambientais em nome do interesse público. Alguns autores enquadram este conflito na dicotomia entre o conceito de land (entendido como um direito ao ambiente) e o conceito de landscape (integrante de um direito do ambiente): Phil Macnaghten e John Urry, in Contested Natures. Sage, London: 1999, p.307.

${ }^{2}$ João Lutas Craveiro, Teresa Oliveira e Álvaro Pereira, in Valorização e Protecção da Zona Costeira Portuguesa. Relatório Final, Relatório 414/03-NESO, ed. LNEC, Lisboa: 2003.
} 


\section{RerCED光A}

$>$ Dossier

linhas de água, orografia ou zonas de menor elevação por classes de altitude, e orla costeira por NUTIII). A análise de cluster dá origem a um dendograma que permite ilustrar a dinâmica da agregação de casos (NUTIII) semelhantes e as distâncias dos casos mais atípicos ou diferentes atendendo às variáveis seleccionadas, método de agregação e medida das diferenças (o efeito de escala das variáveis foi neutralizado com recurso à estandardização das mesmas). A Figura 1 ilustra o dendograma. Replicaram-se os resultados fazendo variar o método de agregação e a medida das diferenças não se tendo apurado diferenças significativas no confronto dos diversos resultados assim obtidos (Quadro 1).

Figura 1: Dendograma (Método Ward)

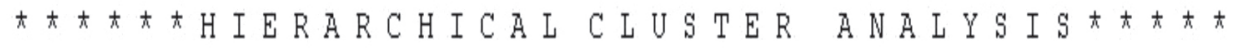

Dendrogram using ward Method

Rescaled Distance Cluster Combine

$\begin{array}{lllllll}\text { C A S E } & 0 & 5 & 10 & 15 & 20 & 25\end{array}$

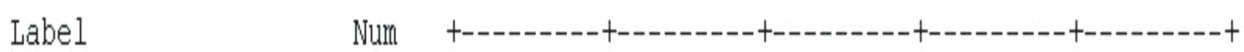

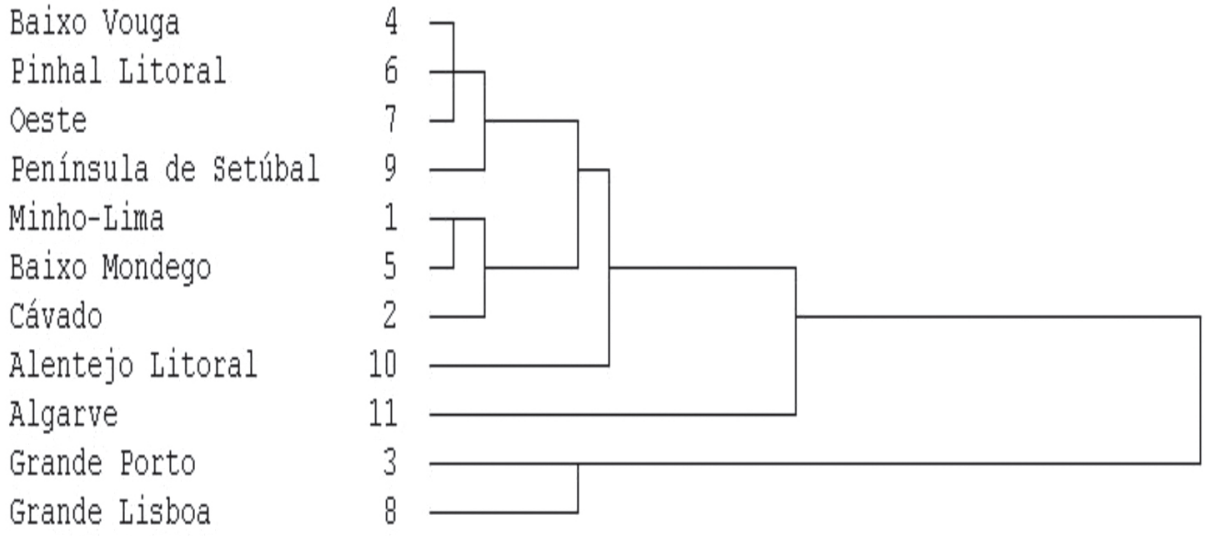

A análise de clusters é uma técnica descritiva privilegiada em ciências sociais e ambientais, possibilitando a identificação das principais homogeneidades e diferenças estruturais podendo ter como variável nominal, em função da qual a agregação dos casos é processada, a região ou uma unidade espacial de referência. No caso presente, dimensões relacionadas com a população (volume e densidade popu-lacionais, graus de con-centração urbana, alojamentos familiares, por ex.), e variáveis económicas e ambientais (pessoal ao serviço de empresas, índice de poder de compra, infra-estruturas de ambiente, recursos de saúde e de protecção civil, dinâmicas de construção urbana, entre outras) discriminam as Grandes Áreas Metropolitanas de Lisboa e do Porto. 
Quadro 1: Comparação de resultados entre técnicas de análise de clusters

\begin{tabular}{|l|c|c|c|}
\hline \multicolumn{1}{|c|}{$\begin{array}{c}\text { Número de Clusters } \\
\text { Método de agregação de casos e medida das diferenças }\end{array}$} & $\mathbf{3}$ & $\mathbf{4}$ & $\mathbf{5}$ \\
\hline Método Ward/Quadrado das distâncias euclidianas & $11 / 11$ & $11 / 11$ & $11 / 11$ \\
\hline Método do Vizinho mais próximo/ Quadrado das distâncias euclidianas & $10 / 11$ & $9 / 11$ & $11 / 11$ \\
\hline Método do Vizinho mais distante/ Quadrado das distâncias euclidianas & $10 / 11$ & $8 / 11$ & $10 / 11$ \\
\hline Método do Vizinho mais próximo/ Distâncias euclidianas & $10 / 11$ & $9 / 11$ & $11 / 11$ \\
\hline Método do Vizinho mais distante/ Distâncias euclidianas & $10 / 11$ & $10 / 11$ & $10 / 11$ \\
\hline
\end{tabular}

(Congruência máxima=11/11)

Nos resultados das técnicas de análise de clusters saliente-se que a região algarvia surge como uma situação particular, diferenciando-se quer das Grandes Áreas Metropolitanas quer das restantes zonas costeiras do Continente português. O Algarve (NUTIII) distingue-se, assim, essencialmente, pelo factor do turismo (estabelecimentos hoteleiros, número de hóspedes e média de dormidas por hóspede, unidades de consumos de água e taxas de crescimento migratório, por ex.). As restantes zonas costeiras apresentam resultados intermédios, duma forma geral, mas maiores desequilíbrios urbanos (índice de primazia ou volume populacional da cidade principal sobre a segunda maior cidade), taxas de crescimento natural negativas, maiores áreas médias percorridas por incêndios florestais, e um maior número de associações ambientalistas ${ }^{3}$ entre outras variáveis. As zonas costeiras continentais portuguesas podem, assim, ser discriminadas em função de homogeneidades e diferenças estruturais com base num conjunto de variáveis socioeconómicas e ambientais, recortando-se do restante território continental a especificidade da região algarvia e a dinâmica das áreas metropolitanas de Lisboa e Porto (Mapa 1). Um maior número de clusters revelaria outras diferenças específicas (da Península de Setúbal ou do Litoral Alentejano), mas o objectivo desta análise conjuga-se com a selecção de três casos de estudo, por áreas homogéneas, e por regiões diferentes no País.

Mapa 1: Grandes áreas homogéneas ao longo da linha da costa continental portuguesa

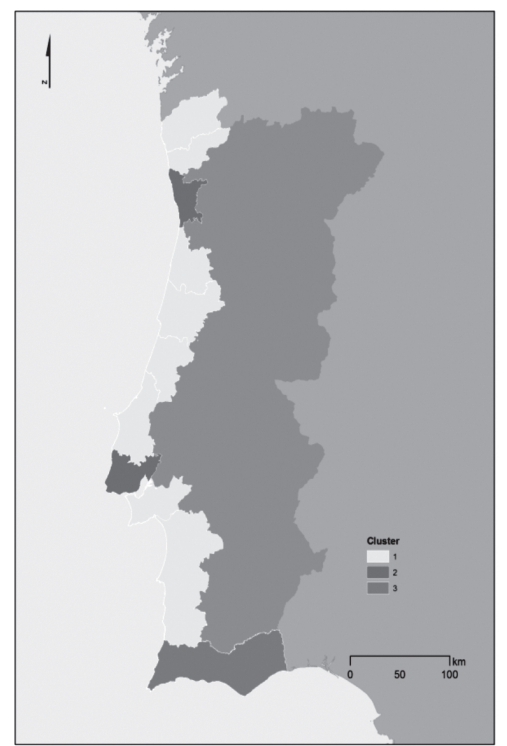

3 Este resultado deve dever-se a associações de carácter local, pois se o número de associações por cem mil habitantes é elevado (1,8 contra cerca de 1 para o resto do País), já o número médio de associados dá uma perspectiva totalmente diferente registando 7 vezes menos de associados que as Grandes Áreas Metropolitanas de Lisboa e Porto. 


\section{$\operatorname{RerCED\varrho ̈UA~}$}

$>$ Dossier

Se a ecologia humana analisa as interdependências entre os sistemas sociais e naturais é preciso reconhecer, à partida, a importância de um pluralismo epistemológico e o confronto, na razão empírica, entre indicadores de diversa ordem, tanto mais encontrando-se em jogo o estudo sobre a resiliência dos territórios humanizados e a capacidade de resposta a riscos derivados das alterações climáticas 4 . José Luís Zêzere alerta no mesmo sentido, recorrendo ao aumento do número de ocorrências provavelmente associado a mudanças climáticas globais, sublinhando a importância das dimensões analíticas sobre a população, equipamentos e actividades, entre outros elementos de vulnerabilidade, enfatizando a necessidade de mapear a ocupação de territórios sujeitos a riscos de inundações, movimentos de vertente e erosão do litoral ${ }^{5}$. Contudo, o desenvolvimento de uma análise sobre vulnerabilidades, sociais e territoriais, como dos conflitos ambientais e a auscultação de peritos e de representantes de interesses requer uma escala de análise mais pormenorizada, com o recurso a casos de estudo. Nesta fase, o projecto dá conta da diversidade das zonas costeiras continentais portuguesas, não se tendo apurado realidades surpreendentes face ao conhecimento sociológico já produzido sobre a humanização dos territórios e as formas de uso e ocupação do solo. Saliente-se também que a existência de uma certa relação, a apurar nos casos de estudo, entre zonas de estuário ou com rede hidrográfica mais densa e as densidades populacionais ${ }^{6}$, sujeitando as comunidades humanas a uma maior exposição ao risco de erosão também não é um dado inédito mas reforça a necessidade do recurso a informação de diversa ordem (Mapas 2 e 3).

Mapa 2: Densidades populacionais

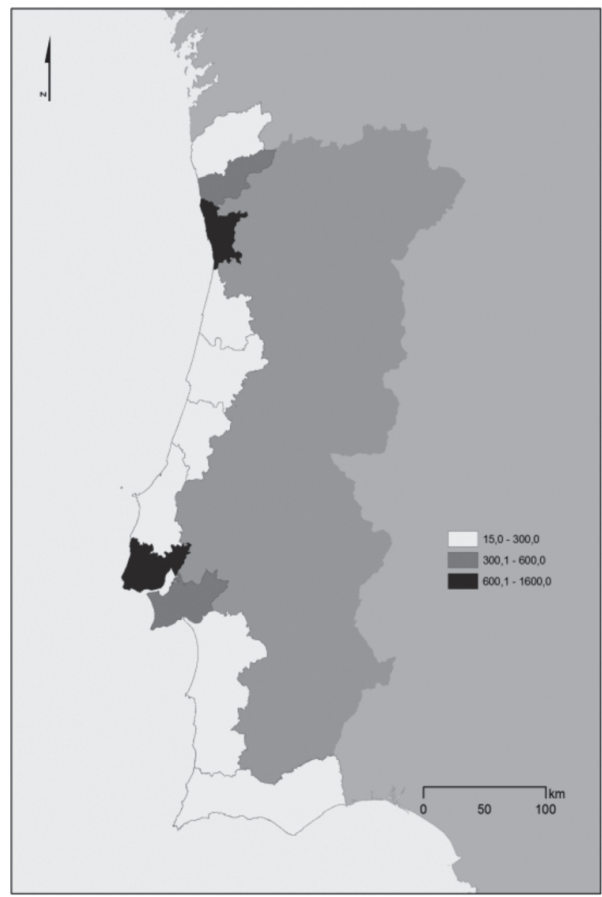

Mapa 3: Áreas junto de Rios?

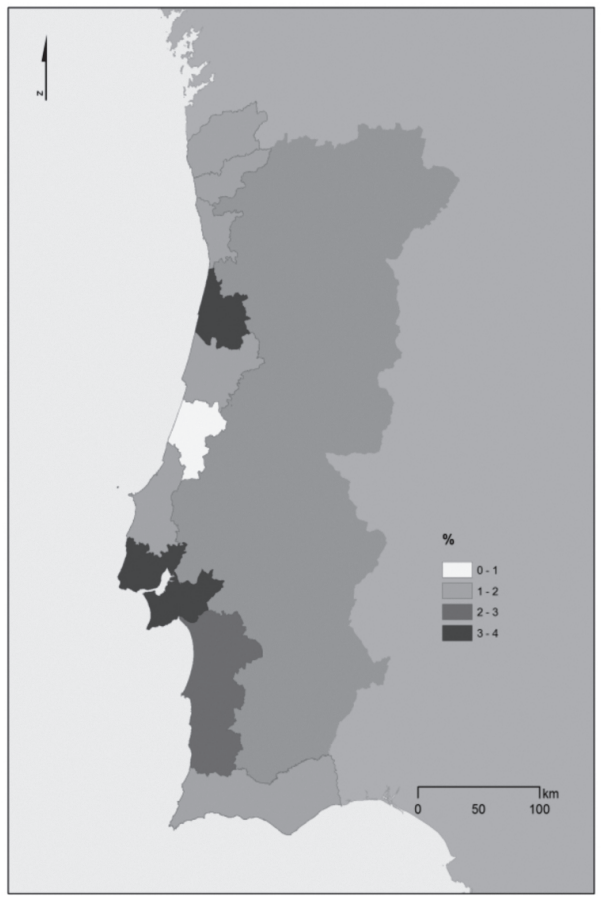

4Thaddeus Miller, Timothy Baird, Caitlin Littlefield et all, in Epistemological Pluralism: Reorganizing Interdisciplinary Research. Ecology and Science, 13(2), 43: 2008.

${ }^{5}$ José Luís Zêzere, in Riscos e Ordenamento do Território. Inforgeo, Julho: 2007 (p.61).

${ }^{6}$ Os dados sobre a população reportam-se ao Censos de 2001. Refira-se, contudo, que a maior parte dos dados utilizados na análise de cluster têm data mais recente, dizendo respeito a dados de 2007, 2008 e 2009. No caso da população e alojamentos optou-se pelo recurso ao Censos de 2001.

7 Variável construída através da criação de um buffer ou zonamento em redor dos troços dos rios principais e na relação (percentagem) entre essa área ou buffer e a área total da respectiva NUTIII. 


\section{$\operatorname{RerCED\varrho ̋̈UA~}$

Refira-se, a propósito, o carácter histórico de uma ocupação urbana que privilegiou os grandes estuários e cursos de água como vias de comunicação e transporte, definindo um padrão de humanização do território que ainda hoje se mantém ${ }^{8}$. Devido à provável subida das águas dos oceanos, no decurso das alterações climáticas, as zonas dos estuários constituem-se também zonas críticas de vulnerabilidade e de risco.

As questões das vulnerabilidades não podem ser dissociadas da análise da dinâmica dos factores de pressão (urbanização, turismo...), do tipo de ocorrências perniciosas associadas a fenómenos naturais ou induzidos e da forma como as desigualdades sociais se transformam em desigualdades ambientais9. A possível sobreposição entre uma estratificação social e ambiental representa, aliás, uma dimensão fulcral de análise em ecologia humana como em sociologia do ambiente ${ }^{10}$. Paradoxalmente, apesar de todo o progresso técnico e material conseguido após a revolução industrial, o triunfo da modernidade (com seus modelos de protecção civil e políticas de promoção do bem-estar) parece ser responsável pelo crescimento exponencial das vulnerabilidades sociais e fragilidades dos sistemas urbanos face aos riscos naturais e induzidos ${ }^{11}$. 0 estudo dos conflitos ambientais, a explorar pelo projecto RENCOASTAL, privilegia os contextos de vulnerabilidade social e fragilidade urbana, no sentido de discriminar, em zonas construídas com frente marítima, as populações e as suas actividades, os recursos de protecção civil e as soluções adaptativas protagonizadas face à erosão costeira. Duma forma simples e esquemática, argumenta-se que os territórios de risco expressam uma exposição a situações ambientais potencialmente danosas em virtude das formas de uso e ocupação do solo, na correspondência directa entre os riscos ambientais (naturais e induzidos) e as actividades humanas (Figura 2).

Figura 2: Correspondência entre riscos ambientais e actividades humanas ${ }^{12}$

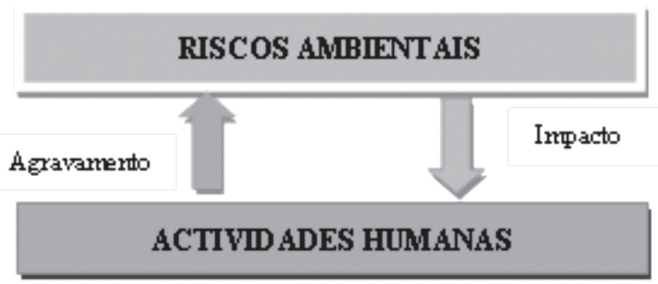

A próxima fase do projecto RENCOASTAL, através da selecção de casos de estudo e identificação de comunidades humanas expostas ao risco de erosão, permite numa escala muito mais pormenorizada, a exploração das percepções sociais do risco e o confronto entre soluções protagonizadas da engenharia civil. Basicamente, as soluções de defesa da orla costeira podem dividir-se entre soluções infra-estruturais de carácter pesado (construção de esporões, ou barreiras fixas ao longo da costa, por exemplo) ou ligeira (alimentação artificial de praias e preservação do cordão dunar, por exemplo). Se, no passado, as soluções desenvolvidas apontavam mais no sentido das intervenções pesadas, hoje as soluções ligeiras, de colaboração com os sistemas naturais, parecem reunir as simpatias dos técnicos e surgem prescritas por políticas ambientais e de ordenamento da orla costeira.

\footnotetext{
${ }^{8}$ Teresa Salgueiro, A Cidade em Portugal. Uma Geografia Urbana. Ed. Afrontamento, Porto: 1992.

9 Timothy O’Riordan, Environmental Science for Environmental Management. Prentice Hall, Harlow: 2000 (p.165).

${ }^{10}$ João Lutas Craveiro, in Ambiente Urbano: Desigualdades e Constrangimentos na Cidade de Lisboa, Sociologia, Problemas e Práticas, n.15: 1994.

${ }^{11}$ Darryl S.L. Jarvis, in Ulrich Beck, Globalization and the Rise of Risk Society: a Critical Exegetic Analysis, Global Society, Vol. 21, No1, January, 2007: p.5.

${ }^{12}$ Adaptado de José Luís Zêzere, op. cit.: p.6o.
} 


\section{$\operatorname{RerCED\varrho ̈UA~}$}

$>$ Dossier

Contudo, é comum encontrarem-se situações mistas, com intervenções intrusivas e pesadas ao longo da linha da costa (Foto 1) e, em simultâneo, face ao interesse das zonas balneares, a adopção de medidas como a alimentação artificial de extensões de areal e de praia. É o caso da Costa da Caparica, que se constitui como um caso de estudo do projecto RENCOASTAL. A zona da Costa da Caparica parece, assim, representar um contexto interessante de estudo onde soluções de tipo diferente têm sido defendidas, embora com um amplo recurso a soluções pesadas (Foto 2$)^{13}$. Pode dizer-se, contudo, que as intervenções ligeiras são, hoje, a opção mais frequentemente utilizada na Europa, apesar das circunstâncias e registos históricos diferentes. A título de exemplo, refira-se que o Reino Unido iniciou em 1962 a alimentação artificial de praias (tendo abandonado em 1972 a prática de transferir sedimentos de umas praias para outras, optando então por efectuar as dragagens nas respectivas praias submersas), enquanto que a Alemanha iniciou, ainda em 1951, a alimentação artificial de praias. Refira-se ainda o caso particular e histórico da Holanda, com um sistema complexo de protecção da orla costeira, promovendo também a alimentação artificial de praias. Países como a Itália, França e Espanha têm também na protecção do seu litoral uma das mais importantes políticas ambientais de defesa do seu território ${ }^{14}$.

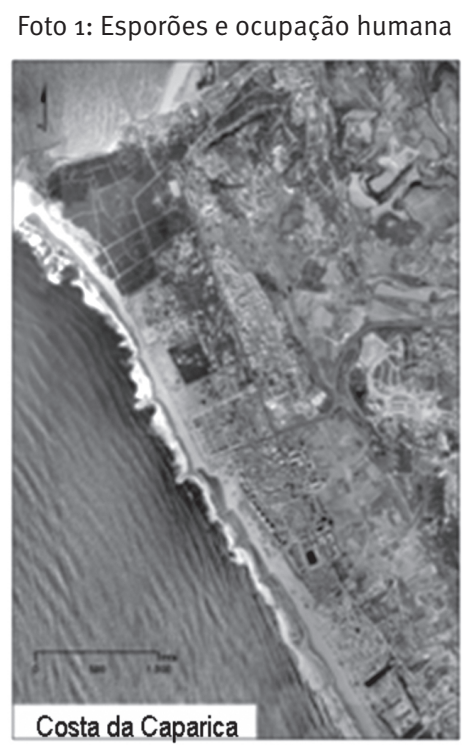

Espinho, em Portugal, parece constituir outro caso de estudo interessante, a desenvolver pelo projecto RENCOASTAL, remontando ao século XIX as primeiras obras de defesa da orla costeira, com construções de madeira para impedir o galgamento das águas do mar. Nos troços a Norte situam-se, aliás, as situações mais críticas de erosão costeira, atendendo a taxas de recuo médio anual superiores a 3 metros por ano $^{15}$. Pela discriminação processada pela análise de clusters, um possível terceiro caso de estudo situar-se-á na região Algarvia, seleccionando-se as zonas a estudar através da sua pertinência territorial face ao risco de erosão costeira, variedade do tipo de construções urbanas (incluindo-se construções amovíveis e apoios de praia) e alimentação artificial das praias.

\footnotetext{
${ }_{13}$ Fotografia do projecto RENCOASTAL datada de 23 de Outubro de 2010.

${ }^{14}$ Ana Ramos-Pereira, in Sistemas Litorais: Dinâmicas e Ordenamento. Finisterra, XI.III, 86, 2008: p.23.

${ }^{15}$ São os casos de Espinho-Cortegaça, Costa Nova-Vagueira e Furadouro: Hélder Careto e Susana Lima, in Turismo e Desenvolvimento Sustentável (Vol.2), ed. GEOTA, Lisboa: 2007 (p.132).
} 


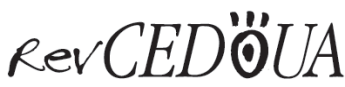

$>$ Dossier

Apenas os casos de estudo (Costa da Caparica, Espinho e Algarve ${ }^{16}$ ) e a aproximação ao jogo dos actores sociais, aos seus interesses e percepções do risco, permitirão uma mais profunda compreensão do potencial de conflito que a regulação ambiental representa entre reguladores e utilizadores ou entre a definição do interesse público, cuja legitimidade é reforçada pela urgência da adaptação e mitigação face às alterações climáticas, e o interesse dos particulares. Questiona-se também, aqui, em que medida o recurso autoritário do ambiente faz prevalecer, por sobre a dinâmica da sociedade civil e os direitos políticos de participação, a coerção das opções necessárias e urgentes que, elegidas em nome do colectivo e em contextos de crise, dispensam a controvérsia dos particulares. Uma dimensão a privilegiar, na monitorização das soluções protagonizadas e no confronto de alternativas, prende-se com o sentido da equidade social e ambiental. Procura-se assim escrutinar, no âmago das políticas e nas soluções técnicas face aos riscos ambientais, o exercício de uma ética da responsabilidade e a sustentabilidade dos territórios humanizados.

Foto 2: Costa da Caparica

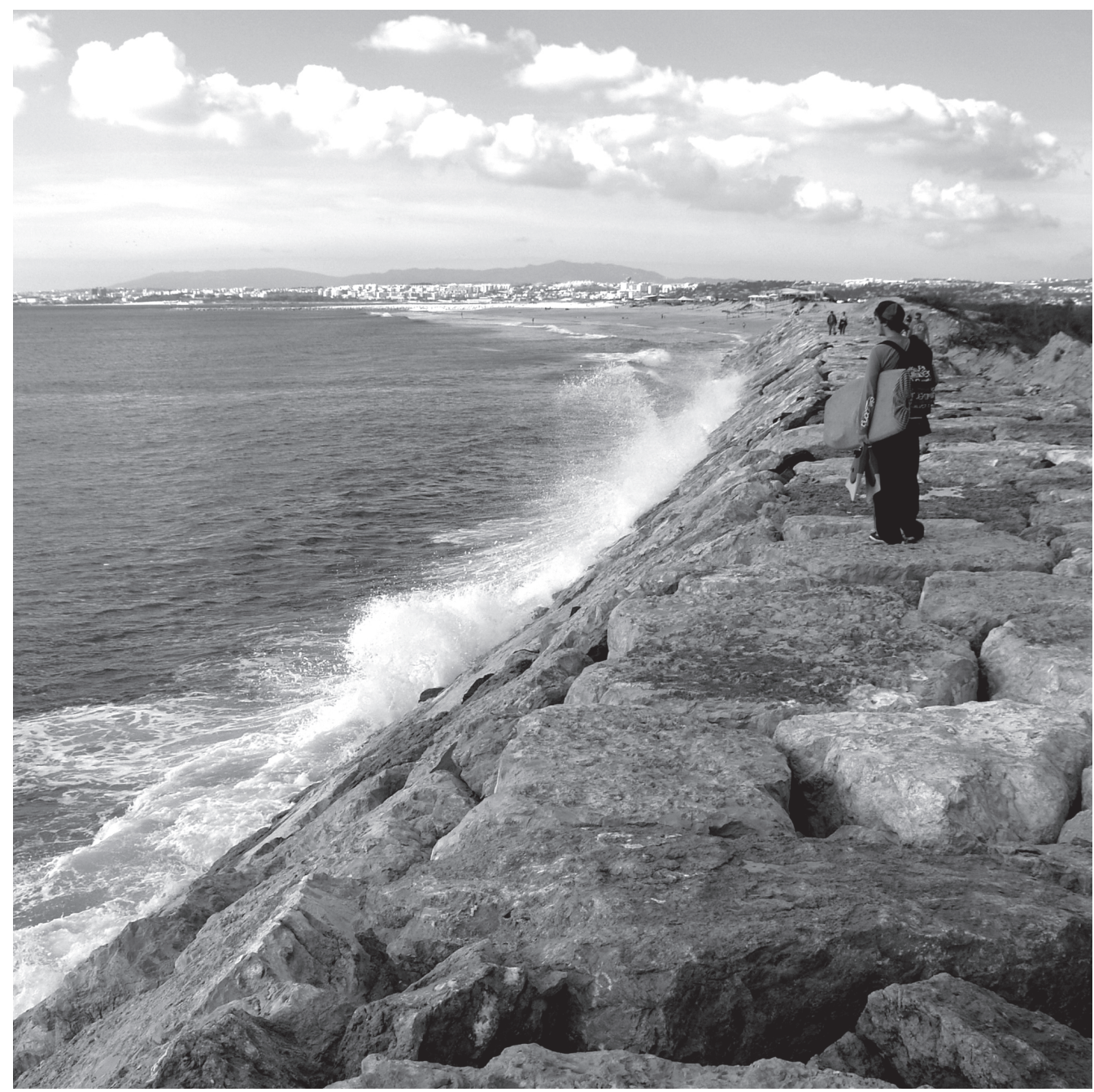

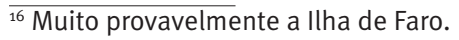




\section{$\operatorname{RerCEDळ̋UUA~}$}

$>$ Dossier

Anexo: Tabela de variáveis

\begin{tabular}{|c|c|c|c|}
\hline Clusters & \begin{tabular}{|l|} 
Litoral excepto \\
Cluster $2 \mathrm{e} 3$
\end{tabular} & \begin{tabular}{|l|} 
Grandes Áreas \\
Metropolitanas
\end{tabular} & $\begin{array}{l}\text { Regiāo do } \\
\text { Algarve }\end{array}$ \\
\hline Variáveis & CLUSTER 1 & CLUSTER 2 & CLUSTER 3 \\
\hline \multicolumn{4}{|l|}{ \% Áreas menos elevadas (até 50m t/NUTSIII) 1982} \\
\hline \multicolumn{4}{|l|}{ \% Área Protegida por NUTIII (1991) } \\
\hline \multicolumn{4}{|l|}{ Buffer/Zona 100 metros margens de rios principais } \\
\hline \multicolumn{4}{|l|}{ Linha da costa por NutllI (média Km por NUTIII) } \\
\hline \multicolumn{4}{|l|}{ Densidade populacional (hab/km2) 2008} \\
\hline \multicolumn{4}{|l|}{ Uso do solo urbano (ha) 2008} \\
\hline \multicolumn{4}{|l|}{ Uso do solo para turismo (km2) 2008} \\
\hline \multicolumn{4}{|l|}{ Uso do solo Equipamentos e Parques (km2) 2008} \\
\hline \multicolumn{4}{|l|}{ Uso do solo para Indústrias (km2) 2008} \\
\hline \multicolumn{4}{|l|}{ \% População residente em cidades > 10000 hab (2008) } \\
\hline \multicolumn{4}{|l|}{ População residente em lugares censitários (2001) } \\
\hline \multicolumn{4}{|l|}{ Isolados (população residente) 2001} \\
\hline \multicolumn{4}{|l|}{ População residente em lugares menos de 2000 hab (2001) } \\
\hline \multicolumn{4}{|l|}{ População residente em lugares mais de 2000 hab (2001) } \\
\hline \multicolumn{4}{|l|}{ Superficie (média há NUTIII) (2008) } \\
\hline \multicolumn{4}{|l|}{ Poder de Compra (\%Continente) 2008} \\
\hline \multicolumn{4}{|l|}{ Indice de Primazia urbano (2008) (pop. $1^{\mathrm{a}}$ cidade $/ 2^{\mathrm{a}}$ cidade) } \\
\hline \multicolumn{4}{|l|}{ Alojamentos familiares clássicos ocupação sazonal (2001) } \\
\hline \multicolumn{4}{|l|}{ Alojamentos familiares clássicos ocupação habitual (2001) } \\
\hline Alojamentos familiares clássicos (2006) & & & \\
\hline Número Edificios construidos (2006) & & & \\
\hline Superficie total das obras concluidas (2006) & & & \\
\hline Número Estabelecimentos hoteleiros (2008) & & & \\
\hline Número Hóspedes Estabelecimentos hoteleiros (2008) & & & \\
\hline Receitas $€$ em ambiente (2006) & & & \\
\hline \% Pop servida ETARs (2007) & & & \\
\hline Número ONGAs por cem mil hab (2006) & & & \\
\hline Número de Associados de ONGAs por 1000 hab (2008) & & & \\
\hline Consumo água m 3 habitante/ano (2007) & & & \\
\hline Despesas em ambiente $€$ habitante (2006) & & & \\
\hline Número de Incêndios florestais/ocorrências (2008) & & & \\
\hline Área ardida (ha) 2008 & & & \\
\hline Área média ardida por ocorrência (2008) & & & \\
\hline Taxa Área florestal ardida (acumulado) por NUTSIII (2008) & & & \\
\hline Taxa crescimento natural da População humana (2009) & & & \\
\hline Taxa crescimento migratório da População humana (2009) & & & \\
\hline Indice de dependência de Idosos (\%) 2009 & & & \\
\hline İndice de Longevidade (\%) 2009 & & & \\
\hline Índice de dependência de Jovens (\%) 2008 & & & \\
\hline População estrangeira solicitou residência por Habitante (2006) & & & \\
\hline Número de Hospitais (2008) & & & \\
\hline Farmácias e postos farmacêuticos móveis (2008) & & & \\
\hline Número de Centros de saúde (2008) & & & \\
\hline Taxa Abstenção Câmaras Municipais (2005) & & & \\
\hline Taxa abstenção Parlamento Europeu (2004) & & & \\
\hline Coeficiente Variação Ganhos Médios Mensais (2007) & & & \\
\hline Veículos novos vendidos por local de residência (NUTIII) (2007) & & & \\
\hline Pessoal ao serviço em presas (2007) & & & \\
\hline Pessoal nas pescas (2007) & & & \\
\hline Pessoal na Educação (2007) & & & \\
\hline Pessoal na Saúde e Acção Social (2007) & & & \\
\hline Tonelada Equivalente Petróleo para automóvel por habb.2008) & & & \\
\hline Número médio dormidas em estabelecimentos hoteleiros (2008) & & & \\
\hline Número hóspedes em estabelecimentos hoteleiros (2008) & & & \\
\hline Número Bombeiros por localidade (NUTIII) (2008) & & & \\
\hline
\end{tabular}

Zonas costeiras continentais portuguesas:

Valor igual ou superior à média total.....

Valor inferior à média

total.....

Número Bombeiros por localidade (NUTIII) (2008)

João Lutas Craveiro, Sociólogo, Investigador do Laboratório Nacional de Engenharia Civil, Núcleo de Ecologia Social do Departamento de Edifícios, Investigador-Coordenador do Projecto RENCOASTAL

Iva Miranda Pires, Geógrafa, Docente da Universidade Nova de Lisboa, Faculdade de Ciências Sociais e Humanas, Investigadora do Projecto RENCOASTAL

Isabel Duarte de Almeida, Bióloga, Docente da Universidade Lusíada, Investigadora do Projecto RENCOASTAL

Óscar Emanuel Antunes, Geógrafo, Bolseiro FCT do Projecto RENCOASTAL 